\title{
A HERMENÊUTICA ISOMÊMICA E A TEORIA NEOINSTITUCIONALISTA DO \\ PROCESSO: conjecturas para legitimidade na construção de provimentos no paradigma do Estado Democrático de Direito
}

Marcos Paulo Andrade Bianchini*

Felipe de Almeida Campos*

\section{RESUMO}

O estudo propôs verificar a possibilidade da hermenêutica isomênica, segundo as conjecturas da Teoria Neoinstitucionalista do Processo, a fim de conferir legitimidade na construção de provimentos no paradigma do Estado Democrático de Direito. O trabalho tem natureza compreensivo analítica, pois buscou reconstruir os dados analisados na perspectiva do Estado Democrático de Direito.

Palavras chave: hermenêutica; legitimidade; interpretação; Teoria Neoinstitucionalista do Processo; Estado Democrático de Direito.

\section{THE ISOMEMIC HERMENEUTICS AND THE TEORIA}

\section{NEOINSTITUCIONALISTA DO PROCESSO: Conjectures for legitimacy in the}

\author{
construction of provisions in the paradigm of the Democratic State of Law
}

The study proposed to verify the possibility of isomeric hermeneutics, according to the conjectures of the Teoria Neoinstitucionalista do Processo, in order to confer legitimacy in the construction of provisions in the paradigm of the Democratic State of Law. The work has an analytical, comprehensive nature, since it sought to reconstruct the analyzed data from the perspective of the Democratic State of Law..

Keywords: hermeneutics; legitimacy; interpretation; Neoinstitutionalist Theory of Process; Democratic State of Law.

* Mestre em Direito Público Especialista em Direito Penal e Processo Penal. Coordenador e professor da Graduação em Direito da Faculdade Pitágoras em Itabira/MG e Ribeirão das Neves/MG. Advogado militante. Email: marcosbianchini@ hotmail.com

* Mestre em Direito Público pela Universidade FUMEC de Belo Horizonte. Professor da Graduação em Direito da Faculdade Pitágoras em Itabira/MG e Ribeirão das Neves/MG. Assessor Parlamentar. Email: felipe.a.campos@educadores.net.br

Rev. de Argumentação e Hermenêutica Jurídica | e-ISSN: 2526-0103| Goiânia | v. 5 | n. 1 | p. 55-75| Jan/Jun. 2019 


\section{INTRODUÇÃO}

A igualdade (isonomia) formal é um dos dogmas herdados pelo Estado Democrático de Direito, que foi tido como conquista no Estado Liberal, e está presente no caput do art. $5^{\circ}$ da CRFB/1988, onde prescreve que "todos são iguais perante a lei".

No entanto, vê-se que se trata de uma igualdade assimétrica, pois vige a ideia de que o Estado, seja ele Legislador, Juiz ou Administração, está em uma ordem hierárquica superior e sobreposta em relação aos cidadãos (povo).

Somado a isso, existem inúmeras situações do cotidiano que suscitam conflitos humanos que não estão lastreadas e prevista em normas escritas. Tais situações conferem liberdade ao Estado, que com o poder de império, realiza construções hermenêuticas e decide de forma desvinculada aos afetados o que torna a argumentação das partes inócua, porque, nessa hipótese, as partes não participam isomenicamente da construção do provimento.

A isonomia que reclama o Estado Democrático de Direito não se restringe na igualdade perante a lei para o exercício do contraditório e da ampla defesa. A isonomia tem que estar fundada em um ordenamento jurídico que expresse uma teoria processual que viabilize um sistema normativo que possibilite aos intérpretes atuação segundo um discurso lógico-jurídico para criação (instituinte), interpretação (constituinte) e aplicação (constituído) de direitos.

Dessa forma, os órgãos estatais seriam os instrumentos do processo aberto à qualquer do povo, propiciando uma fiscalidade irrestrita (concreta e abstrata) do controle procedimental de constitucionalidade e contemplando uma hermenêutica isomênica adequada ao Estado de Direito no eixo da Teoria do Discurso que exige compreensão única para todos os operadores do direito e não somente para segmentos privilegiados da comunidade jurídica.

Por isso, se torna imperiosa a busca de uma teoria da decisão jurídica que permita aos afetados a criação, modificação, interpretação e extinção das normas do ordenamento jurídico, possibilitando a sindicabilidade dos cidadãos para além da consciência solitária e da visão egoísta do decisor.

Por isso, a pesquisa procura responder a seguinte pergunta: A hermenêutica isomênica proposta pela Teoria Neoinstitucionalista do Processo permite a abertura da 
interpretação à comunidade jurídica legitimada (povo), e contribui para a legitimidade das decisões produzidas no paradigma do Estado Democrático de Direito?

O trabalho parte da hipótese de que o cidadão por meio do processo e seus princípios institutivos (contraditório, ampla defesa e isonomia), no exercício da hermenêutica isomênica, segundo a teoria Neoinstitucionalista do processo, pode participar da interpretação das normas do ordenamento jurídico, uma vez que é garantido ao cidadão se valer do processo como espaço crítico-argumentativo para ver concretizados seus direitos fundamentais, que possuem características de certeza, liquidez e exigibilidade.

O objetivo geral da pesquisa é demonstrar que as conjecturas da Teoria Neoinstitucionalista do Processo, por meio da hermenêutica isomênica, possibilitam a abertura da interpretação à comunidade jurídica legitimada (cidadãos), isso para além da decisão que deriva da consciência solitária do decisor, o que oportunizará decisões jurídicas legítimas e democráticas.

Para se alcançar o objetivo geral se considerou os seguintes objetivos específicos: a) estudar a Teoria Neoinstitucionalista do Processo e as conjecturas do Conhecimento Objetivo de Karl Popper; b) entender hermenêutica isomênica proposta pela Teoria Neoinstitucionalista do Processo.

A metodologia utilizada tem como dados primários da pesquisa a Constituição da República Federativa do Brasil de 1988 (CRFB/1988), a obra o conhecimento objetivo de Karl Popper e a Teoria Neoinstitucionalista do Processo proposta pelo Professor Rosemiro Pereira Leal, a legislação, as leis, as resoluções e as demais normas, bem como a jurisprudência dos Tribunais Superiores; e são dados secundários da pesquisa as opiniões doutrinárias referentes a hermenêutica filosófica e o Direito Constitucional, bem como suas interpretações, e as legislações comentadas. O trabalho tem natureza compreensivo-analítica, pois busca reconstruir os dados analisados na perspectiva do Estado Democrático de Direito.

\section{O CONHECIMENTO OBJETIVO DE KARL POPPER E A TEORIA NEOINSTITUCIONALISTA DO PROCESSO: CONJECTURAS PARA DECISÕES JURÍDICAS DEMOCRÁTICAS}

Rev. de Argumentação e Hermenêutica Jurídica | e-ISSN: 2526-0103| Goiânia | v. 5 | n. 1 | p. . 55-75| Jan/Jun. 2019 
Tiago Cappi Janini \& Amanda Juncal Prudente

A Teoria Neoinstitucionalista do processo tem a gênese de suas conjecturas na teoria do conhecimento objetivo de Karl Popper, e defende que somente o conhecimento objetivo pode justificar um enunciado científico.

Popper inicia a tessitura de suas ideais implementando uma distinção entre o que denominou de conhecimento objetivo e conhecimento subjetivo.

Em sua obra "Conhecimento objetivo" propõe uma epistemologia racionalista ao tecer críticas à indução como formulada por David Hume, amplamente divulgada na obra "Investigação acerca do entendimento humano" (HUME, 1972), ao sustentar sinteticamente que: a) a origem do conhecimento é a crença de que o futuro será como o passado; b) essas crenças e expectativas decorrem das regularidades como as coisas acontecem (fenômenos da natureza, teorias, etc.); c) o homem é habituado raciocinar a partir de exemplos que tem experiência para outros exemplos que não tem experiência (POPPER, 1975, p. 15-16).

Assim, o conhecimento objetivo, contrapondo o conhecimento subjetivo/psicológico de Hume que tem como fundamento uma fé irracional, parte da premissa de que todas as experiências e sensações (os sentidos como meio de aquisição do conhecimento) devem ser encaradas como teorias hipotéticas ou conjecturais, em suma, como suposições (POPPER, 1975, p. 20).

A teoria do conhecimento de Hume tem que a descoberta de eventos futuros (desconhecidos) advém da experiência vivida com os eventos do passado (conhecidos), estabelecendo a relação de causa e efeito que são descobertos pela experiência sensitiva, e não pela razão (HUME, 1972, p. 32).

A regularidade e a crença dogmática de expectativas imutáveis trazem conforto para o homem, porém, quando ocorre a ruína dessas crenças e regularidades os homens tornam-se infelizes e são impelidos ao desespero na busca de novas teorias que the deem suporte temporário. São nesses momentos que se manifesta a lógica do descobrimento (POPPER, 1975, p. 34)

O conhecimento pautado na observação e crença nas regularidades conduz a uma atitude dogmática da ciência, que é traduzida na possibilidade da existência de um conhecimento certo e seguro. Essa crença produz dogmas e faz com que o conhecimento posto e o mundo acontecido sejam inquestionáveis. Por isso, para Popper o caráter crítico da ciência é o que oportuniza a sua racionalidade (SIECZOKOWKI, 2006, p. 49).

Rev. de Argumentação e Hermenêutica Jurídica | e-ISSN: 2526-0103| Goiânia| v. 5 | n. 1 | p. . 55-75| Jan/Jun. 2019 
A busca pelo descobrimento, que Popper também admite ser um instinto inato do homem, só é racional por meio do conhecimento objetivo.

Defende Popper que "Só o conhecimento objetivo é criticável: o conhecimento subjetivo só se torna criticável quando se torna objetivo. E torna-se objetivo quando dizemos o que pensamos; e mais ainda quando o escrevemos, ou imprimimos" (POPPER, 1975, p. 35).

Por outro lado, o conhecimento subjetivo é aquele formado pelos sentimentos de convicção e por crenças que originadas das experiências dedutivas que advém das repetições do passado e das manutenções históricas de determinadas ideais que formam o senso comum que Popper apelidou de "teoria do balde mental” (POPPER, 1975, p. 14-15).

O conhecimento subjetivo é aquele que só existe em um lugar: no estado psicológico e mental do sujeito, que não pode ser testado, apreciado e muito menos visto pelos demais sujeitos (comunidade científica).

Já o conhecimento objetivo é aquele que se mostre falseável, suscetível de ser submetido à prova.

Qualquer enunciado que não seja suscetível a testes intersubjetivos de eliminação de erros não pode ser considerado conhecimento científico.

Conclui Popper que "Por mais intenso que seja um sentimento de convicção, ele jamais pode justificar um enunciado, estar certo da evidência de minhas percepções; tomado pela intensidade de minha experiência, toda dúvida pode parecer-me absurda" (POPPER, 2013, p. 43).

O autor busca a superação do então reinante conhecimento subjetivo, que se origina do sujeito conhecedor, do "ser subjetivo que conhece" (POPPER, 1975, p. 77).

Popper identifica um problema existente entre o mundo 1 (dos estados e processos físicos) e o mundo 2 (dos estados e processos mentais), que seria um problema de interação, que Descartes chamaria de problema corpo-alma, mas que Popper chamou de interação estados físicos-estados mentais (POPPER, 2004, p. 18).

Assim, para solucionar o problema corpo-mente, que é o relacionamento do mundo 1 e 2, Popper descortina a realidade do mundo 3, que tem o mundo 2 como intermediário entre os mundos 1 e 3 (POPPER, 2004, p. 22).

Dessa forma, o conhecimento objetivo consistiria em

[...] suposições, hipóteses ou teorias, habitualmente publicadas sob a forma de livros, revistas ou palestras. Consiste também em problemas não resolvidos e em argumentos pró ou contra diversas teorias rivais. Por consequiência, é obvio que o conhecimento objectivo forma parte do mundo 3 dos produtos da mente. Deste

Rev. de Argumentação e Hermenêutica Jurídica | e-ISSN: 2526-0103| Goiânia| v. 5 | n. 1 | p. . 55-75| Jan/Jun. 2019 
Tiago Cappi Janini \& Amanda Juncal Prudente

modo, o progresso do conhecimento objectivo representará parte do crescimento do mundo 3 (POPPER, 2004, p. 25).

Há casos que se manifesta uma concorrência de teorias, cada qual dando origem a novas experiências - a tentativa de fazer fracassar as teorias - e a novos problemas tem-se o Debate Crítico Apreciativo (DCA), com o qual se procura decidir quais das teorias rivais são fortes para sobreviver e quais devem ser eliminadas por completo. Como aduz Popper: "a evolução do conhecimento pode ser encarada como uma luta pela sobrevivência entre teorias em competição". (POPPER, 2004, p. 27).

Popper contava a história de uma comunidade na Índia que acreditava que a vida dos tigres era sagrada. $\mathrm{O}$ resultado foi que a comunidade desapareceu e com ela a teoria de que a vida dos tigres é sagrada. Diferente é o conhecimento objetivo “[...] em vez de nós, podemos deixar morrer as nossas teorias objectivas. Na verdade, fazemos o possível por matálas, experimentando-as com rigor antes de as pormos em prática" (POPPER, 2004, p. 28).

O progresso do conhecimento para Popper se dá com a submissão do conhecimento e suas teorias ao teste de falibilismo/falseamento em que só sobreviverão as teorias mais resistentes a tais testes.

A teoria de Popper parte sempre da ideia de que todo conhecimento é falseável, uma vez que ao longo do progresso científico podem surgir ou serem propostas teorias que se mostrem mais "imunes" ou "rígidas" aos testes de eliminação de erro.

Isso faz com que "[...] certas teorias, em certos momentos do tempo, sejam preferidas a outras, à luz de nossa discussão crítica, que consiste de refutações tentadas, inclusive testes empíricos" (POPPER, 1975, p. 75).

As teorias formuladas pertencem ao mundo 3, e as teorias são importantes e indispensáveis, uma vez que "sem elas, não nos poderíamos orientar no mundo - não conseguiríamos viver. Até mesmo as nossas observações são interpretadas com a sua ajuda" (POPPER, 1996, p. 77).

Uma decisão jurídica que considera e tem como fundamento o conhecimento objetivo se mostra mais plausível e mais adequada no Estado Democrático de Direito. O conhecimento subjetivo, a crença cega nas regularidades e a manutenção histórica de dogmas inquestionáveis só fazem o homem viver enclausurado e dominado pela manutenção do poder.

Apreendido os rudimentos da teoria do conhecimento objetivo de Karl Popper, o trabalho passará a analisar quais os reflexos na teoria Neoinstitucionalista do processo.

Rev. de Argumentação e Hermenêutica Jurídica | e-ISSN: 2526-0103| Goiânia| v. 5 | n. 1 | p. . 55-75| Jan/Jun. 2019 
Rosemiro Pereira Leal migrou as conjecturas de Popper para a ciência do Direito, considerando a sociedade na pós-modernidade "uma sociedade aberta" com o rompimento do que denominou "miséria do historicismo" e a superação de um Estado dogmático, com a proposta de criação, transformação e reconstrução do Estado e demais instituições através de um "método de encaminhar o conhecimento científico: o falseasionismo (falseabilidade)" (LEAL, 2013, p. 1).

O processo na pós-modernidade se revela como uma conquista histórica-teórica das garantias e direitos fundamentais constitucionalizados que busca a superação do indesejado desequilíbrio jurídico e econômico das camadas da sociedade (LEAL, 2014, p. 21).

Por isso, o processo não é mais tido como instrumento ou método de atuação da jurisdição, como defendem os teóricos da escola instrumentalista ao conceber o processo como uma Relação Jurídica.

Para a escola instrumentalista, que tem o processo como relação jurídica entre o juiz e às partes como defende Bülow (1964, p.1-4), não existe uma relação jurídica (autorjuiz-réu), e sim uma relação subjetiva (que tem como objeto direitos subjetivos) e voluntarista (autor exige do réu direito que sustenta ser seu) com um processo instrumental e teleológico.

No Estado Democrático de Direito o processo não é mais mero instrumento da jurisdição, e também não se confunde com a figura do procedimento, seja no âmbito legislativo, administrativo ou judicial.

Nos casos em que se produz uma decisão jurídica observando apenas um procedimento ou tendo o processo como um meio, pode até haver jurisdição ou atividade legislativa ou administrativa, mas não há processo.

Frisa-se que a teoria instrumentalista do processo ocupa lugar de destaque e é grande influenciadora da academia brasileira, tendo como seus principais teóricos Antônio Carlos de Araújo Cintra, Ada Pellegrini Grinover e Cândido Rangel Dinamarco (2006).

A teoria instrumentalista, como denuncia Rosemiro Pereira Leal, se firma na crença de que decididores/intérpretes (administrador, juiz ou legislador) detém varas de condão, fórmulas e palavras mágicas que fazem crer que sejam capazes de concorrer para a paz social, a felicidade paradisíaca do homem e a efetivação do interesse público, isso tudo pode meio de uma autoridade que se coloque como um pai ou um salvador "ético, irrepreensível, sábio, puro, vestal, ou prodigamente justo e talentoso” (LEAL, 2014, p. 95).

Rev. de Argumentação e Hermenêutica Jurídica | e-ISSN: 2526-0103| Goiânia | v. 5 | n. 1 | p. . 55-75| Jan/Jun. 2019 
Tiago Cappi Janini \& Amanda Juncal Prudente

Por outro lado, o processo, segundo a teoria Neoinstitucionalista, é definido atualmente com as garantias principiológicas da reserva legal consubstanciadas nos direitos da isonomia, da ampla defesa e do contraditório que antecipadamente são assegurados na Constituição (LEAL, 2014, p. 22).

As constituições, nesse sentido, deixam de ser um estatuto totalizante e exclusivo da atividade estatal, e passa ser um texto articulador e legitimante de instituições jurídicas, em que o Estado se apresenta como uma delas, não mais como uma entidade superior, soberana e absoluta (LEAL, 2014, 29).

Na pós modernidade, o que se tem é um pós mundo posto pelo homem sem fincas em pressupostos históricos condicionadores. E nesse contexto, o processo se apresenta como “[...] instituição jurídica que ao lado do Estado, do povo, da cidadania, da soberania popular, contém princípios definidos pelo contraditório, da ampla defesa, da isonomia, reunidos pelo instituto do devido processo" (LEAL, 2014, p. 30).

Só é possível uma decisão jurídica legítima que seja fruto do processo considerado como instituição instrumentadora e legitimadora, seja da atividade legislativa, jurisdicional ou administrativa.

Os provimentos das funções do Estado devem ser construídos processualmente pela submissão aos princípios jurisdicionais e constitucionais da cidadania que, a rigor, somente pela observação de tais princípios esta se forma e se afirma. Para a afirmação da cidadania são necessárias múltiplas incursões sobre o conceito de garantia e dos princípios constitucionais do processo, cujo exercício produz legitimidade irrestrita para a fiscalidade processual dos direitos constitucionalizados (LEAL, 2014, p. 31).

Portanto, o processo constitucionalizado, concebido de uma forma jurídicodiscursiva, na estruturação de procedimentos (judiciais, administrativos ou legiferantes) faz com que os provimentos decorrentes (decisões, sentenças e leis) advenham de um compartilhamento dialógico-processual operado por uma comunidade jurídica constitucionalizada que disponha e delibere ao longo da criação, alteração, reconhecimento e aplicação de direitos, e não de estruturas de poderes do autoritarismo sistêmico de órgãos dirigentes, legiferantes e judicantes que representam uma minoria inexpressiva (porém, poderosa) de um Estado ou de uma comunidade política (LEAL, 2014, p. 90). 
Isto é, os verdadeiros legitimados do processo constitucionalizado (povo/cidadão), atuam de forma autônoma e livre por meio de um discurso democrático em um espaço processualizado.

Nessa conjectura, a garantia de direitos pela instituição do processo constitucionalizado não decorre mais de uma autoridade, que esteja comprometida com a Administração Pública de uma realidade "econômica-social extraordenamental, mas de um nível teórico-jurídico de uma comunidade política que não mais permitiria retrocessos em seus fundamentos constitucionais de processualização" dos direitos e garantias de seus direitos fundamentais que são certos, líquidos e exigíveis (LEAL, 2014, p. 91).

O processo, nessa concepção, não é espaço restrito aos especialistas e aos detentores de uma linguagem discursiva exclusiva para acessar os espaços públicos de deliberação.

O fato de grande parte do povo, por exclusão social ou cognitiva, não ter acesso à compreensão das garantias e direitos processuais que foram instituídos pela Comunidade Política, faz com que seja necessário "erigir a Constituição como médium institucional que, na contrafactualidade, há de tornar apto o povo, por direitos fundamentais implementados, a conjecturar, concretizar ou recriar o discurso da Lei Constitucional Democrática" (LEAL, 2014, p. 91).

A garantia principiológica constitucional do devido processo converte-se numa garantia que não pode ser afastada ou esquecida, pois decorre das conquistas teóricas da humanidade no empreendimento secular de resistência à tirania e dominação. Assim, o devido processo irradia interferência expansiva e fecunda (influência direta e operante) nas estruturas procedimentais da Administração, do Legislativo e do Judiciário, alcançando todas as funções do Estado (LEAL, 2014, p. 88).

Os princípios autocríticos do contraditório, da ampla defesa e da isonomia definem a teoria Neoinstitucionalista do processo que conjectura um pacto de significância como teoria de constitucionalidade para gerenciar e balizar a construção, aplicação e extinção dos direitos aos legitimados do processo (LEAL, 2013, p. 44).

Por contraditório tem-se “[...] a dialogicidade necessária entre interlocutores (partes) que se postam em defesa ou disputa de direitos alegados, podendo, até mesmo, exercer a liberdade de nada dizerem (silêncio), embora tendo direito-garantia de se manifestarem" (LEAL, 2014, p. 99).

Rev. de Argumentação e Hermenêutica Jurídica | e-ISSN: 2526-0103| Goiânia | v. 5 | n. 1 | p. . 55-75| Jan/Jun. 2019 
Tiago Cappi Janini \& Amanda Juncal Prudente

André Cordeiro Leal leciona que "o contraditório deixa de ser mero atributo do processo e passa à condição de princípio (norma) determinativo de sua própria inserção na estruturação de todos os procedimentos preparatórios dos atos jurisdicionais" (LEAL, 2002a, p. 88).

Vê-se que há superação da ideia instrumentalista de contraditório que vai além de "igualdade de oportunidade", sendo esta a isonomia que é o direito assegurador de igualdade de realização construtiva do procedimento (LEAL, 2014, p. 99).

Alerta Rosemiro Pereira Leal que é “oportuno distinguir isonomia e simétrica paridade", sendo a simétrica paridade uma "condição já constitucionalmente assegurada dos direitos fundamentais dos legitimados ao processo quanto à vida digna, liberdade e igualdade (direitos líquidos e certos) no plano constituinte do Estado Democrático de Direito" (LEAL, 2014, p. 99).

A isonomia, como princípio institutivo da teoria Neoinstitucionalista, diz respeito à qualidade de que são investidos os legitimados do processo (povo) para criação e definição do direito, na atividade legiferante, judicial e administrativa, respectivamente.

Os conteúdos processuais dialógicos da isonomia - que são a isotopia, isomenia e isocrítica - é consequência lógica de um povo concretizador e criador de sua própria igualdade jurídica pelo devido processo constitucional.

Assim, a isonomia em sua base decisória representa " igualdade de todos perante a lei (isotopia), igualdade de todos para interpretar a lei (isomenia) e a igualdade de todos de fazer, alterar ou substituir a lei (isocrítica)" (LEAL, 2014, p. 49).

O princípio da ampla defesa diz respeito aos limites temporais que oportuniza às partes o contraditório, com isso traduz-se na "garantia da plenitude da defesa em tempo e modo suficiente para sustentá-la" (LEAL, 2014, p. 100).

A adoção dos princípios autocríticos do contraditório, da ampla defesa e da isonomia propicia a derrocada os “"eus' solipsistas, inatos e pressupostamente contextualizados em seus absolutos e estratégicos saberes deontológicos e corretivos de justificação e aplicação do Direito" (LEAL, 2014, p. 104).

Percebe-se que os princípios institutivos da teoria Neoinstitucionalista do processo abre a possibilidade da efetivação de um espaço linguístico autocrítico para compartilhamento intersubjetivo de sentido da normatividade nas bases instituinte (criação), constituinte (interpretação) e constituída (aplicação) dos direitos.

Rev. de Argumentação e Hermenêutica Jurídica | e-ISSN: 2526-0103| Goiânia | v. 5 | n. 1 | p. . 55-75| Jan/Jun. 2019 


\section{A HERMENÊUTICA ISOMÊNICA}

A igualdade (isonomia) formal é um dos dogmas herdados pelo Estado Democrático de Direito, que foi tido como conquista no Estado Liberal, e está presente no caput do art. 5 da CRFB/1988, onde prescreve que "todos são iguais perante a lei".

No entanto, vê-se que se trata de uma igualdade assimétrica, pois vige a ideia de que o Estado, seja ele Legislador, Juiz ou Administração, está em uma ordem hierárquica superior e sobreposta em relação aos cidadãos (povo).

Somado a isso, existem inúmeras situações do cotidiano que suscitam conflitos humanos que não estão lastreadas e prevista em normas escritas. Tais situações conferem liberdade ao Estado, que com o poder de império, realiza construções hermenêuticas e decide de forma desvinculada aos afetados "o que torna a argumentação das partes inócua, porque, nessa hipótese, as partes não participam isomenicamente da construção do provimento" (LEAL, 2010, p. 271).

A isonomia que reclama o Estado Democrático de Direito não se restringe na igualdade perante a lei para o exercício do contraditório e da ampla defesa. A isonomia tem que estar fundada em um ordenamento jurídico que expresse uma teoria processual que viabilize um sistema normativo que possibilite aos intérpretes atuação segundo um discurso lógico-jurídico para criação (instituinte), interpretação (constituinte) e aplicação (constituído) de direitos (LEAL, 2010, p. 271).

Ao invés da isonomia aplicada à interpretação, tomada em seu sentido clássicodogmático, Rosemiro Pereira Leal propõe uma hermenêutica isomênica que seria

[...] instituto operacional do princípio da legalidade, define-se pela oportunidade de colocar todos os destinatários normativos (intérpretes) em simétrica posição ante idêntico referente lógico-jurídico construtivo, aplicativo, modificativo ou extintivo do sistema jurídico (LEIS). É o devido processo, no sentido da teoria neoinstitucionalista, que é o referente lógico-jurídico (interpretante) a balizar os limites hermenêuticos de um sistema jurídico de "Estado Democrático de Direito" em concepções de uma sociedade aberta (LEAL, 2010, p. 272).

Para a operacionalização da hermenêutica isomênica a Teoria Neoinstitucionalista rompe com a ideia generalizada do que seja o "discurso", que adquiriu sentido polissêmico no direito e foi embrenhado no senso comum da ciência dogmática do direito, a fim de eternizar o obscurantismo e a permanência da autoridade decisora hercúlea (LEAL, 2010, p. 272).

Rev. de Argumentação e Hermenêutica Jurídica | e-ISSN: 2526-0103| Goiânia| v. 5 | n. 1 | p. . 55-75| Jan/Jun. 2019 
Tiago Cappi Janini \& Amanda Juncal Prudente

Para reconstrução do sentido do discurso no Estado Democrático de Direito a teoria Neoinstitucionalista se vale da teoria do interpretante presente na obra "Discurso, texto e significação" do linguista Edward Lopes (1978).

A teoria do interpretante aponta que as teorias semânticas admitem ao menos três postulados, são eles: a sensatez da mensagem, o caráter oculto do significado e a inteligibilidade do sentido (LOPES, 1978, p. 3).

Nessa ordem, em primeiro a sensatez da mensagem afirma que o discurso tem um sentido, mas esse sentido não é imanente, porque se assim fosse não seria necessário interpretá-lo. Isso significa que o "sentido do discurso está fora dele, situando-se, por assim dizer, em um espaço que o transcende e ao qual chamamos texto" (LOPES, 1978, p. 3).

Em segundo, o caráter oculto do significado diz respeito ao sentido procurado no texto. Logo, há sempre sentido no discurso por vários textos que assumem e possuem uma plurissignificação, visto que o discurso tem como objeto (texto) um conhecimento aberto a uma pluralidade de leituras. Essa multisignificação do discurso desemboca a um "não saber" que é extremamente perturbador (LOPES, 1978, p. 3).

Esclarece o autor que o discurso perturba porque pertence ao "outro", que se manifesta como um oponente. Como o "outro", o discurso também é enigmático se tornando um problema a resolver, pois é tomado de inúmeros sentidos e isso escapa ao domínio do homem. "Só posso dominar o que conheço; procurar o sentido do discurso é uma das maneiras pelas quais as pessoas manifestam um envergonhado desejo de dominação" (LOPES, 1978, p. 4).

Isso revela uma das grandes potencialidades do discurso: ser instrumento de dominação do homem.

A manipulação dos sentidos se revela como um modo eficaz de dominação do homem pelo homem, sendo este um dos instrumentos com esse fim mais utilizados na história.

Explica Edward Lopes (1978, p. 4) sobre o discurso como instrumento de dominação:

[...] supomos que uma teoria semântica que se dedicasse a observar, atentamente, o que é que as pessoas fazem com as palavras quando se comunicam com outras pessoas, desembocaria, fatalmente, em uma teoria da ideologia, em cujo âmbito se esclareceria o que é que as pessoas fazem com outras pessoas quando se utilizam de palavras. Analisados, uma a um, todos os modos de dominação que o homem inventou ao longo dos séculos para relacionar-se com o seu próximo, nenhum é mais eficiente do que o da manipulação dos sentidos. Aquele que manipula os sentidos do

Rev. de Argumentação e Hermenêutica Jurídica | e-ISSN: 2526-0103| Goiânia | v. 5 | n. 1 | p. . 55-75| Jan/Jun. 2019 
discurso transforma-se no árbitro todo-poderoso da comunidade para a qual define o que venha a ser valor e antivalor; é ele quem assinala os objetivos a serem perseguidos pelo grupo, dita as regras de comportamento que hão de dirigir a ação singular dos indivíduos na tentativa de realização de seus valores, pune e recompensa. Pois, como os mitos de sempre demonstraram, só o que sabe quer, só o que sabe pode, só o que se sabe faz.

Percebe-se que há no discurso uma ideologia de dominação que se vale da manipulação de sentidos advinda do arbítrio de um ente todo poderoso que determina os rumos de uma comunidade e opera, também, a resolução dos conflitos insurgentes.

Em terceiro e último tem a inteligibilidade do sentido, que reconhece no autor do discurso a única autoridade (o autor aqui é tido como titular da autoridade) para dizer o que o discurso significa.

Só o produtor da mensagem era reconhecido com a competência necessária para definir o que seu discurso queria dizer, o que ele podia dizer, e, o que ele efetivamente dizia.

Se um destinatário da mensagem propusesse interpretações indesejáveis, a autoridade do discurso (o autor) atribuiria inépcia do ouvinte, e desse modo, desqualificaria o subentendido para requalificá-lo de mal-entendido.

Dessa forma percebe-se que a“"...] multisignificação do discurso estava, então - e ainda está, para aqueles que nisso acreditam - a serviço de um privilégio da significação que é a camuflagem do privilégio do mando de uma autorictas única e indiscutível” (LOPES, 1978, p. 5).

Assim, a única autoridade apta para conferir sentido ao discurso seria o seu autor do texto, e nunca os leitores que seriam os destinatários interpretantes.

Rosemiro Pereira Leal utilizou desta lição e leciona que, nesse sentido, o legislador seria o autor autoritário do discurso legal (seu genuíno locador a inocular a mens legislatoris), o Juiz e o Administrador (decisores) seriam os sublocadores a engendrar um texto (juízos de aplicação como mens legis), sendo que o "justo" legal implicaria no ajuste que o autor do texto (intérprete-decisor) realizasse da mens legislatoris segundo sua inteligência de sublocador do sentido da lei (mens legis) para prestar a jurisdição ou para o exercício da atividade administrativa (LEAL, 2010, p. 275).

Para superar o problema do autoritarismo da interpretação do autor (única autoridade da interpretação) que é veiculado pela semântica, Edward Lopes encontra na linguística o meio para modificar essa situação. Esclarece o autor que:

Um dos maiores serviços prestados pela linguística à ciência moderna foi, certamente, o de ter contribuído tão poderosamente para modificar essa situação, ao 
insistir no fato de que a semântica deve se preocupar com o sentido do discurso tal como ele se deixa decodificar no interior do código que serviu para sua codificação. $\mathrm{O}$ desenvolvimento do conceito de função metalingüística permitiu compreender o sentido como uma propriedade do código, não de uma pessoa, e possibilitou, em conseqüência, na medida em que os códigos são bens coletivos, possuídos, igualmente, pelo destinador e pelo destinatário da mensagem, denunciar o monopólio do sentido que era exercido pelo sujeito da enunciação. Sabe-se, hoje, que se um discurso admite $n$ sentidos, eles podem ser reduzidos, todos, em um nível superior, a um meta-sentido que os reabsorva conjuntamente, estando eles, portanto, hierarquizados por relações de dominação intradiscursiva (LOPES, 1978, p. 5).

Deste modo, a linguística promoveu uma autovirada ao propor a decodificação do sentido do discurso a partir de um código que se presta à própria definição do discurso e não mais a partir das "multissignificações" de sentidos que se extraem dos textos, que por sua vez, estão conectados às impressões oriundas da mente do locador e sublocador do discurso. A decodificação do discurso, nessa auto-reviravolta linguística, migra do âmbito privado e enigmático do texto dos decisores para o recinto intradiscursivo que é viabilizado pelo "código" (interpretante) instituinte e constituinte do discurso Constitucional (co-institucional) constituído, que é o devido processo segundo a teoria Neoinstitucionalista (LEAL, 2010, p. 274).

\section{Rosemiro Pereira Leal esclarece que}

Ao trazermos a lúcida e criativa contribuição do professor Edward Lopes com sua teoria do interpretante que substituiu a "variável" da declaração do sentido de discurso engastada no "sujeito da enunciação" (locador-locadotário do discurso) pela "variável" dos "códigos sociais" de sentido como "bens coletivos" a dessujeitizarem a linguagem, percebe-se que a intenção do linguista foi eliminar a plurissignificação de textos originária do mentalismo do locador-intérprete do discurso, a fim de estabelecer um "nível heterodiscursivo" como fonte de sentidos coletivamente construída (LEAL, 2010, p. 274-275).

O autor leciona que "[...] o decisor não pode ser portador prodigioso de melhores argumentos e de melhor razão ao interpretar a lei ante a comunidade jurídica de legitimados ao processo (povo)" (LEAL, 2013, p. 18).

O devido processo, segundo a Teoria Neoinstitucionalista, assim entendido

[...] assume atributos de um neoparadigma com "função metalinguística" a demarcar um "meta-sentido" como fundamento do sistema jurídico-democrático para a criação de uma sociedade aberta derivada de uma comunidade de legitimados ao processo (povo) aptos a exercerem uma simétrica paridade interpretativa dos direitos legislados (hermenêutica isomênica) (LEAL, 2010, p. 274).

Essa metalinguagem seria empreendida no movimento entre texto e discurso com vínculo ao código (interpretante como regulador do sentido intradiscursivo), impedindo que o texto (sempre de origem precompreensiva ao discurso) possa desgarrar-se do interpretante 
(referente-código) intradiscursivo que dá suporte a uma prática de simétrica paridade interpretativa para todos (LEAL, 2010, p. 275).

Dessa forma, o devido processo, segundo a teoria Neoinstitucionalista, é o espaço crítico que forma base instituinte e constituinte de direitos, tendo estes a natureza de liquidez, certeza e exigibilidade.

É a hermenêutica isomênica que possibilita a compreensão de um direito democrático que tenha na sua base decisória a garantia de igualdade de todos perante a lei (isotopia), igualdade de todos para interpretar a lei (isomenia) e a igualdade de todos de fazer, alterar ou substituir a lei (isocrítica).

Para Popper a linguagem comporta quatro funções, são elas as funções: expressiva, sinalizadora, descritiva e argumentativa. As funções expressiva e sinalizadora, que também chamou de funções inferiores, pertencem ao mundo animal. Já a função descritiva e a função argumentativa (funções superiores) estão presentes na linguagem humana e delas decorrem a evolução do raciocínio e da racionalidade (POPPER, 1975, p. 216).

A função descritiva opera a descrição de conjecturados estados de coisas, esboçados em forma de teorias e hipóteses.

É na função argumentativa que se encontra disciplinada a discussão crítica que seria "um meio de controle: são um meio de eliminar erros, um meio de seleção. Resolvemos nossos problemas propondo experimentalmente várias teorias e hipóteses concorrentes [...] submetendo-as a discussões críticas e a testes empíricos de eliminação de erros" (POPPER, 1975, p. 220).

Leciona Popper que com a função argumentativa é possível falar que

[...] não só nossas teorias nos controlam, como podemos controlar nossas teorias (e mesmo nossos padrões; existe aqui uma espécie de retrocarga). E se nos sujeitamos a nossas teorias, fá-lo-emos então livremente, após deliberação; isto é, depois da discussão crítica de alternativas e depois de escolher livremente entre as teorias concorrentes, à luz daquela discussão crítica. (POPPER, 1975, p. 220-221).

Por isso que no Direito democrático é tão imperiosa a adoção dessa visão argumentativa da linguagem no processo hermenêutico, uma vez que as interpretações e teorias podem ser trocadas, substituídas e até eliminadas.

Porém, entre interpretações possíveis e concorrentes "há de se buscar o melhor padrão teórico-regulador para não abolir emocionalmente o sistema que se sustenta por uma testificação teórica continuada à realização de propósitos e objetivos” (LEAL, 2013, p. 81).

Rev. de Argumentação e Hermenêutica Jurídica | e-ISSN: 2526-0103| Goiânia| v. 5 | n. 1 | p. . 55-75| Jan/Jun. 2019 
Tiago Cappi Janini \& Amanda Juncal Prudente

A busca por soluções, e em especial, a busca por intepretações adequadas e compatíveis com o Estado Democrático de Direito, surge diante do incômodo, do desconforto, da apreensão e do mal-estar quando se está diante de um problema. Daí inicia-se o movimento de antecipação dos meios possíveis de reagir com a conjectura de teorias e interpretações que sejam submetidas a testes de experiência de erro e seus possíveis resultados (POPPER, 1975, p. 226-227).

\section{Rosemiro Pereira Leal leciona que}

Daí, uma sociedade (que é uma teoria), que se queira aberta, construir-se-á ante teorias rivais, mas, para isso, é necessário problematizá-las, o que, em direito, para uma sociedade aberta, no discurso de testificação, impõe escolher uma entre as teorias processuais do discurso como a melhor (mais resistente) a tornar constitucionalmente disponíveis, para todos, conjecturas falseabilizantes (argumentações) continuadas com o fim de instituir e constituir juridicamente (estabilizar) uma forma linguística de compartilhamento de sentidos de vida, liberdade e dignidade. Com efeito, uma Teoria da Constituição democrática, na concepção pós-moderna da falibilidade dos sistemas, há de passar pela compreensão curricular da teoria do processo como enunciativa (descritivo-argumentativa) dos direitos fundamentais (fundantes) da correlação humana contraditório-vida, ampla defesa-liberdade e isonomia-dignidade (LEAL, 2013, p. 83).

Desse modo, a hermenêutica isomênica, com as suas características extrínsecas e intrínsecas, permite e torna possível a falseabilidade das teorias e interpretações concorrentes. Ademais, se mostra mais adequada para a interpretação, não apenas dos conceitos jurídicos indeterminados, mas de todo o Direito em seus níveis instituinte, instituído e constituído.

Somente teorias rigorosas e criticamente testificadas em todos os graus de pesquisas podem propor uma construção de mundo (LEAL, 2013, p. 7).

Deesa forma, as normas do sistema constitucional não seriam " reserva do jurista, mas um fio condutor para o uso de todos os cidadãos" (FERNANDES, 2012, p. 94).

A proposta é de uma participação da decisão jurídica em um "espaço processualizado em que o povo total da Comunidade Política é, por direito de ação coextenso ao procedimento, a causalidade dos princípios e regras de criação, alteração e aplicação de direitos" (LEAL, 2014, p. 90).

Isso demonstra que falar em interpretação "ao alcance de todos" sem que haja um espaço crítico-deliberativo-argumentativo que considere o povo como legitimado para a interpretação, representa verdadeiro dogma que se presta a dar aparência de procedimentos legítimos que, na verdade, mascaram e confirmam a dominação da autoridade na interpretação.

Rev. de Argumentação e Hermenêutica Jurídica | e-ISSN: 2526-0103| Goiânia | v. 5 | n. 1 | p. . 55-75| Jan/Jun. 2019 
Por isso, só no instituto constitucionalizado do processo, segundo a concepção da Teoria Neoinstitucionalista, é possível se falar em hermenêutica isomênica que oportunize a interpretação e o espaço de decisibilidade que incida desde a criação de direitos (lei) e perpasse por sua incidência, aplicação, extinção ou transformação.

A superação do solipsismo e do monopólio da interpretação pela autoridade se dá por meio do processo como instituição jurídica constitucionalizada no plano instituinte e constituinte do Direito, que tem como primado os princípios do contraditório, da ampla defesa e da isonomia e que tem na linguagem uma acepção "lingüístico-autocrítico coparticipativo de produção, aplicação e extinção da normatividade" (LEAL, 2014, p. 101).

Dessa forma, não há cabimento de se conceber ainda um sujeito conhecedor divinizado que produza uma decisão jurídica a despeito de toda uma comunidade aberta, com base em sua consciência egoísta e solitária.

Somente uma interpretação/teoria que possa ser submetida à crítica e a testes de eliminação de erro, de forma objetiva (e não subjetiva), possibilitando que as conjecturas sejam testadas pelas hipóteses existentes, com possibilidade de exercício da hermenêutica isomênica de todos os legitimados, é capaz de fazer com que a cada momento histórico situado prevaleça uma interpretação/teoria mais resistente a fim de criar, recriar, modificar e extinguir direitos.

\section{CONCLUSÃo}

O trabalho avançou sobre as conjecturas da Teoria Neoinstitucionalista do Processo a partir da Teoria do conhecimento objetivo de Karl Popper. Percebeu-se que o conhecimento subjetivo é aquele formado pelos sentimentos de convicção e por crenças que originadas das experiências dedutivas que advém das repetições do passado e das manutenções históricas de determinadas ideais que formam o senso comum. O conhecimento subjetivo é aquele que só existe em um lugar: no estado psicológico e mental do sujeito, que não pode ser testado, apreciado e muito menos visto pelos demais sujeitos (comunidade científica). Já o conhecimento objetivo é aquele que seja possível ser justificável ou verificável, suscetível de ser submetido à prova. Dessa feita, o conhecimento só se torna objetivo quando dizemos o que pensamos; e mais ainda quando o escrevemos, ou imprimimos.

Rev. de Argumentação e Hermenêutica Jurídica | e-ISSN: 2526-0103| Goiânia | v. 5 | n. 1 | p. . 55-75| Jan/Jun. 2019 
Tiago Cappi Janini \& Amanda Juncal Prudente

O progresso do conhecimento para Popper se dá com a submissão do conhecimento e suas teorias ao teste de falibilismo/falseamento em que só sobreviveram as teorias mais resistentes a tais testes. Dessa forma, a teoria sempre parte da ideia de que todo conhecimento é falseável, uma vez que ao longo do progresso científico podem surgir ou serem propostas teorias que se mostrem mais "imunes" ou "rígidas" aos testes de eliminação de erro.

A partir das conjecturas de Popper a teoria Neoinstitucionalista tem o processo na pós-modernidade como conquista histórica-teórica das garantias e direitos fundamentais constitucionalizados que busca a superação do indesejado desequilíbrio jurídico e econômico das camadas da sociedade. Por isso, o processo não é mais tido como instrumento ou método de atuação da jurisdição, como defende os teóricos da escola instrumentalista, ao conceber o processo com a visão angustiante da Relação Jurídica (autor-juiz-réu).

Por outro lado, o processo, segundo a teoria Neoinstitucionalista, é definido atualmente com as garantias principiológicas da reserva legal consubstanciadas nos direitos da isonomia, da ampla defesa e do contraditório, princípios estes garantidos e assegurados antecipadamente na Constituição.

Só é possível uma decisão jurídica legítima que seja fruto do processo, considerado no trabalho como instituição instrumentadora e legitimadora, seja da atividade jurisdicional como a administrativa.

Portanto, o processo constitucionalizado, concebido de uma forma jurídicodiscursiva, na estruturação de procedimentos (judiciais, administrativos ou legiferantes) faz com que os provimentos decorrentes (decisões, sentenças e leis decorrentes) advenham de um compartilhamento dialógico-processual operado por uma comunidade jurídica constitucionalizada que disponha e delibere ao longo da criação, alteração, reconhecimento e aplicação de direitos, e não de estruturas de poderes do autoritarismo sistêmico de órgãos dirigentes, legiferantes e judicantes que representam uma minoria inexpressiva (porém, poderosa) de um Estado ou de uma comunidade política.

Perquirindo uma proposta de interpretação da lei, percebeu-se que isonomia é o direito assegurador de igualdade de realização construtiva do procedimento. Já os conteúdos processuais dialógicos da isonomia - que são a isotopia, isomenia e isocrítica - é consequência lógica de um povo concretizador e criador de sua própria igualdade jurídica pelo devido processo constitucional. Assim, a isonomia propicia uma hermenêutica isonômica

Rev. de Argumentação e Hermenêutica Jurídica | e-ISSN: 2526-0103| Goiânia| v. 5 | n. 1 | p. . 55-75| Jan/Jun. 2019 
que é a garantia da igualdade de todos perante a lei (isotopia), igualdade de todos para interpretar a lei (isomenia) e a igualdade de todos de fazer, alterar ou substituir a lei (isocrítica).

Concluiu-se que a hermenêutica isomênica arraigada e aplicada no processo, segundo a teoria Neoinstitucionalista, faz do processo uma instituição jurídica constitucionalizada no plano instituinte e constituinte do direito, que se estrutura nos princípios do contraditório, da ampla defesa e da isonomia

Daí a horizontalização das atividades administrativas seria viabilizada por meio do processo, com o exercício da hermenêutica isomênica ao possibilitar a compreensão de um direito democrático que tenha na sua base decisória a garantia de igualdade de todos perante a lei (isotopia), igualdade de todos para interpretar a lei (isomenia) e a igualdade de todos de fazer, alterar ou substituir a lei (isocrítica).

Assim, por meio do processo, assentado nos postulados autocríticos do contraditório, da ampla defesa e da isonomia, é possível concretizar e dar efetividade a um sistema democrático pela constitucionalização respectiva de direitos à vida humana, liberdade e dignidade, isso para toda a comunidade jurídica de legitimados (cidadãos).

Ao final do trabalho concluiu-se que somente pelo processo, como instituição constitucionalizada, o controle judicial que incida sobre a da interpretação dos conceitos jurídicos indeterminados, permite a abertura da interpretação à comunidade jurídica legitimada no exercício da hermenêutica isomênica, de forma que todos os legitimados do processo (povo) tem condições de exercer um direito democrático que tenha na sua base decisória a garantia de igualdade de todos perante a lei (isotopia), igualdade de todos para interpretar a lei (isomenia) e a igualdade de todos de fazer, alterar ou substituir a lei (isocrítica).

\section{REFERÊNCIAS}

BRASIL. Constituição da República Federativa do Brasil de 1988. Disponível em: < http://www.planalto.gov.br/ccivil_03/Constituicao/Constituicao.htm>. Acesso em: 31 Mar. 2019.

BÜLOW, Oskar Von. La Teoria das Excepciones Procesales y Presupuestos Procesales. Buenos Aires: EJEA, 1964, 302 p. 
Tiago Cappi Janini \& Amanda Juncal Prudente

CINTRA, Antônio Carlos de Araújo; GRINOVER, Ada Pellegrini; DINAMARCO, Cândido Rangel. Teoria Geral do Processo. 22. ed. São Paulo: Malheiros, 2006, 383 p.

FERNANDES, Bernardo Gonçalves. Curso de Direito Constitucional. 4 ed. rev., ampl. e atual. Bahia: Juspodivm, 2012, 1.305 p.

HUME, David. Investigação acerca do entendimento humano. São Paulo: Nacional, 1972, $149 \mathrm{p}$.

LEAL, André Cordeiro. Instrumentalidade do processo em crise. Belo Horizonte:

Mandamentos: Universidade FUMEC. Faculdade de Ciências Humanas, Sociais e da Saúde, 2008. 163 p.

LEAL, André Cordeiro. O contraditório e a fundamentação das decisões: no direito processual democrático. Belo Horizonte: Mandamentos, 2002a. 111 p.

LEAL, Rosemiro Pereira. A Principiologia Jurídica do Processo na Teoria Neo-

Institucionalista. Revista Virtuajus, n. 2, 2006. Disponível em:

<http://www.fmd.pucminas.br/Virtuajus/2_2006/Docentes/pdf/Rosemiro.pdf>. Acesso em 08 dez. 2016.

LEAL, Rosemiro Pereira. A Teoria Neoinstitucionalista do Processo: uma trajetória conjectural. Belo Horizonte: Arraes Editores, 2013, 120 p.

LEAL, Rosemiro Pereira. Direitos Fundamentais do processo na desnaturalização dos Direitos Humanos. Revista Virtuajus da PUC Minas. Disponível em:< http://www.fmd.pucminas.br/Virtuajus/1_2006/Docentes/pdf/Rosemiro.pdf>. Acesso em: 05 nov. 2016

LEAL, Rosemiro Pereira. Garantismo Processual e Direitos Fundamentais Líquidos e Certos. Revista Eletrônica de Direito Processual, v. IV, ano 3, Rio de Janeiro, jul./dez. 2009, p. 111-119.

LEAL, Rosemiro Pereira. O due process e o devir processual democrático. Belo Horizonte: Revista da Faculdade Mineira de Direito, v.13, n. 26, jul./dez. 2010.

LEAL, Rosemiro Pereira. O Paradigma Processual ante as sequielas míticas do Poder Constituinte Originário. Revista da Faculdade de Direito da UFMG, Belo Horizonte, n. 53, p. 295-316, jul./dez. 2008, p. 295-316.

LEAL, Rosemiro Pereira. Processo como lei democrática. Belo Horizonte: Fórum, 2010, $306 \mathrm{p}$.

LEAL, Rosemiro Pereira. Teoria geral do processo: primeiros estudos. 10.ed. rev. e aum. Porto Alegre: Síntese, 2011, 293p.

LEAL, Rosemiro Pereira. Teoria processual da decisão jurídica. São Paulo: Landy, 2002b, $206 \mathrm{p}$. 
LOPES, Edward. Discurso, texto e significação: uma teoria do interpretante. São Paulo: Cultrix, 1978, $111 \mathrm{p}$.

POPPER, Karl Raimund. A lógica da pesquisa científica. São Paulo: Cultrix, 2013, 451 p.

POPPER, Karl Raimund. Conhecimento objetivo: uma abordagem evolucionária. Belo Horizonte: Editora Itatiaia, 1975, 394 p.

POPPER, Karl Raimund. Lógica das ciências sociais. 3. ed. Rio de Janeiro: Tempo Brasileiro, 2004, 101 p.

POPPER, Karl Raimund. O conhecimento e o problema corpo-mente. São Paulo: Edições 70, 2004, $212 \mathrm{p}$.

SIECZOKOWKI, João Batista C. O pluralismo da tese dos três mundos de Popper e a crítica de Habermas. Revista Princípios, Natal, vol. 13, números 19-20, jan./dez. 2006, p. 31-55.

STRECK, Lenio Luiz. O que é isto - decido conforme minha consciência? 4. ed. rev. Porto Alegre: Livraria do Advogado, 2013, 120 p. 